\title{
Study on the Definition of the Influence Area of the Station and the Prediction of the Traffic Mode Sharing Rate
}

\author{
Shuangzhou Guo \\ Ningbo City College of Vocational Technology; 9 Xuefu Road, Yinzhou Higher Educational Zone, Ningbo, Zhejiang, P.R. China
}

\begin{abstract}
Studied the theory of integration of rail and bus transit was. Combined with the urban master plan, analysis the two characters, With the study on the characteristics of city tenor city economic developing economic globally and the characteristics of market economy, studied the passenger flow forming mechanism. The influential area of railway station was studied. Surveyed the time difference among walk+rail”, "walk+bus", a model was set up and its algorithm was given, finally the different type station area, transfer and middle station were given.
\end{abstract}

Keywords- rail transit; transfer and feeder; system character; logit model; transit hub theory; layout and location; feeder bus; genetic algorithm

\section{RESEARCH OBJECTIVE}

As an important node of rail transit network, is also an important link between the rail transit and bus transit, the size of the scale and capacity of the station directly affects the cost and efficiency of rail traffic engineering quality. The peak time of the station to attract traffic is an important factor to determine the size of the station [1]. Each station has its own passenger attraction area.

Rail transit station area can affect the scope of influence of important traffic hub point is defined as the track through the bus, this part of the main feeder for rail transit passenger, also is the feeder bus line network planning geographic range, the influence degree of the rail transportation from the railway station to gradually decrease.

General link on the site is divided into two categories, one is the intermediate station, that is, only in the loop, not with other lines intersect, the other is a transfer station, that is, with other lines intersect, there are a large number of passengers in this transfer [2]. There is a difference between these two types of sites.

The experience of the construction of the subway in Japan is that the direct attraction of the station is within $750 \mathrm{~m}$ of each side of the station, and the terminal is the center of the station, and the circle of $750 \mathrm{~m}$ is the radius". According to the thirtysixth International Conference of rail traffic information, "for the majority of the city, the most suitable distance to the rail transit station on foot, in the center of the city is $500 \sim 600 \mathrm{~m}, 800 \sim$ $1000 \mathrm{~m}$ in the edge region of [3].

Through the study of rail transit station area of how to define and identify important steps of rail transit and conventional bus interface is also for the following further study of feeder bus routes to lay the foundation for planning.

\section{DeFinition AND Hypothesis OF THE INFLUence AREA OF RAIL TRANSIT STATION}

Effect of rail transit station area defined, the general method is to walk to the bus station and rail traffic station time difference, residents in the vicinity of the station research model, according to the different sites (transfer station and intermediate station) are given different influence area of [3]. Generally speaking, the station is in direct proportion to the passenger flow, and the location of the station and the distribution of the surrounding infrastructure are defined.

\section{A. Problem Description}

In order to facilitate the study, we start from the simplest and most standard model to explore more complex models. The general characteristics of the ring line network is track two lines or more than one aspect of the intersection in the loop, we assume that the two intersecting lines for perpendicular diameters, the link is a standard circle, the circle center is on the two horizontal line intersection (see Figure 1) [4].

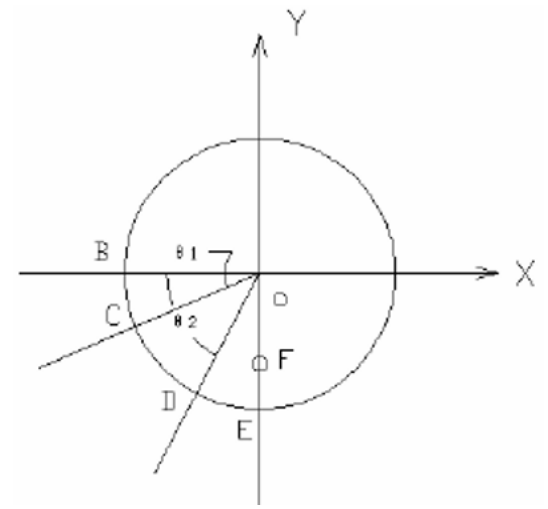

FIGURE I. STANDARD CIRCUIT DIAGRAM

Because of its special symmetry, we only need to study the third quadrant of the middle of the site D and site B can transfer, our task is to study the link within an area where the residents arrived at the downtown route choice is to choose the link on the site, take the rail transit in downtown [4].

1 residents travel, the income level can afford the subway (or light rail) and buses. That is to say, without the restriction of the 
price difference between the bus and the subway, the travel mode can be any one of the two ways.

2) there is a bus stop in the vicinity of the residential area, and we consider the area covered by the bus stop as a particle (the radius of coverage is not more than $500 \mathrm{~m}$ ).

3) the difference of comfort between bus and subway is not quantitative, which can be expressed by utility function.

4) the bus route has non linear coefficient, non linear coefficient is not greater than 1.4 , then, we take $\mathrm{P}=1.2$,

5) when traveling by bus, the average speed is $15 \mathrm{~km} / \mathrm{h}$. The average speed of subway $35 \mathrm{~km} / \mathrm{h}$, pedestrian walking speed $5 \mathrm{~km} / \mathrm{h}$.

6 passengers in the transfer, assuming an average transfer time is $6 \mathrm{~min}$.

7) if the layout of the whole network is in the plane, there is not much fluctuation.
8) there is a bus between two points on the plane. If there is no bus, you can think of these two points can be used to walk or bike travel.

\section{ESTABLISHMENT OF ATtRACTION MODEL FOR RAIL TRANSIT STATION}

There is a starting point $\mathrm{P}$, point $\mathrm{P}$ for travelers from $\mathrm{J}$ station to the destination so the travel time $\mathrm{Q}, \mathrm{Tj}$ fee for all the travel routes of minimum time.

Definition1: $\mathrm{Tj}$ is the starting point for $\mathrm{P}$ transit rail $\mathrm{J}$ site to reach the destination of the shortest travel time $\mathrm{Q}$.

Definition2: all station sites are set to $\mathrm{S} 1$.

Which:

$$
\begin{aligned}
& \mathrm{Tj}=\min \left|\mathrm{Tpj}+\left(\frac{l_{i j}}{35} * 60+\mathrm{Nij} * 6\right)+\mathrm{tiQ}+\mathrm{tc}\right|(\text { Minute), among, } \mathrm{i} \\
& \in \mathrm{S} 1, \mathrm{i} \neq \mathrm{j}
\end{aligned}
$$

$$
\begin{aligned}
\tau \pi \varphi & = \begin{cases}t \text { Average walking time }+ \text { tAverage waiting time }+60 * \frac{l_{p j} * 1.2}{1.5} & \text { when } l_{p j}>500 \mathrm{~m} \\
60 * \frac{l_{p j}}{5} \quad \text { when } l_{p j} \leq 500 \mathrm{~m}\end{cases} \\
\tau \iota_{\Theta} \Theta & = \begin{cases}t \text { Average walking time }+ \text { tAverage waiting time }+60 * \frac{l_{i Q} * 1.2}{1.5} & \text { when } l_{i Q}>500 \mathrm{~m} \\
60 * \frac{l_{i Q}}{5} & \text { when } l_{i Q} \leq 500 \mathrm{~m}\end{cases}
\end{aligned}
$$

$$
\text { tc }=\sum_{i-1}^{k} f_{i}(\text { price })
$$

Which:

$\mathrm{t}_{\mathrm{pj}}$ : Time from $\mathrm{P}$ to $\mathrm{j}$ site

$t_{\mathrm{iQ}}$ : From the I site to the $\mathrm{Q}$ time

$\mathrm{l}_{\mathrm{ij}}$ : From the I site to the shortest path to the $\mathrm{j}$ site, you can use the Dijkstra algorithm

$\mathrm{N}_{\mathrm{ij}}$ : From the I site to the $\mathrm{j}$ site in the shortest path in the number of transfer required, you can use computer programming

$t_{c}$ : The utility value function of the car is measured by the price, the higher the price, the greater the value, the lower the price, the smaller the value

$f_{i}$ (price): The travel time of passenger I section of the route to use a certain travel cost conversion time

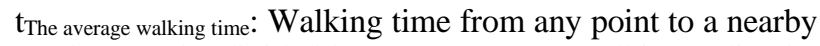
bus station can be divided by $500 \mathrm{~m}$ average walking radius by walking speed $5 \mathrm{~km} / \mathrm{h}$, obtain $\mathrm{t}$ average walking time $=0.1 \mathrm{~h}$;

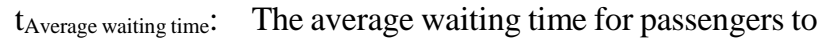
get on the bus station, Value $6 \mathrm{~min}$;

The $\mathrm{P}$ point of the passengers from the $\mathrm{J}$ station, the time spent in Tj must be more than walking to direct bus, and Q Q, the time spent on something from the station I to. That is:

$$
\mathrm{T}_{\mathrm{j}} \leq \mathrm{T}_{\text {Walk straight }} \quad \mathrm{T}_{\mathrm{j}} \leq \mathrm{T}_{\text {Bus direct }} \quad \mathrm{T}_{\mathrm{j}} \leq \mathrm{T}_{\mathrm{i}}(\mathrm{i} \neq \mathrm{j})
$$

Which:

$\mathrm{T}_{\text {Walk straight: }}$ The time required for the direct way to walk from P to q;

$\mathrm{T}_{\text {Bus direct }}$ : From $\mathrm{P}$ to the time required to reach the $\mathrm{Q} \mathrm{Q}$ bus; from $\mathrm{P}$ to the time required for direct way to the bus;

$\mathrm{T}_{\mathrm{i}}$ : From the point of $\mathrm{P}$ through the I station, the minimum time to reach the final q;

Combined with the above analysis, the final results are obtained, That is:

$\mathrm{T}_{\mathrm{j}}=\min (\mathrm{P}$ from $\mathrm{J}$ on the bus, to any route $\mathrm{Q}$ by the time),

Satisfy constraint:

$$
\mathrm{T}_{\mathrm{j}} \leq \frac{l_{p Q}}{5} \quad \mathrm{~T}_{\mathrm{j}} \leq \frac{l_{p Q * 1.2}}{5} \quad \mathrm{~T}_{\mathrm{j}} \leq \mathrm{T}_{\mathrm{j}} \quad\left(\mathrm{i} \in \mathrm{S}_{1} \text { but } \mathrm{i} \neq \mathrm{j}\right)
$$

\section{The Realization of Traffic Mode Choice Model}

There are two main aspects in the implementation of the model. One is the parameter calibration, a calibration using the numerical parameters on calibration, a calibration using the numerical method for calculating the correlation; two is the result of the set plan, any one of these models are just a selection probability value, and the prediction results we need is to make all the residents partition number of selection a mode of transportation, so also will choose the probabilities of individuals into the selection probability of all residents of the partition value, this is a set, can be used in blending method, the steps are as follows: 
1. All the residents in the area are divided into groups (M group), that is, according to certain classification standards will be divided into several types of residents;

2. The average value of each characteristic variable in the sample group is taken as the corresponding characteristic variable;

3. Then we choose these variables directly into the corresponding choice probability model to find the probability of selection of $\mathrm{i}$;

4. The selection probability of each group is determined by the number of each group and the average probability of selecting the I of the selected branch is calculated.

The planning and layout of the railway hub is in the stage of primary road network generation, from the macro level of the road network to determine the location of the railway hub in the planning area should be set. The implementation feasibility study and preliminary design phase in the network design stage and the line, from the railway and the other passenger bus connection way especially discusses location rail hub, to improve the efficiency of the transfer of the hub. The location of mass transit hub is to determine the specific location settings in the hub rail station, according to the other passenger station (or hub) of the situation to determine the location, this problem can be divided into the following three types of [5]:

The simple type of hub location: in other way station (hub) position has been established, only to determine the rail hub location is simple, this problem is more common in rail transportation and the city's traffic hub in connection;

The interactive type hub location: in other way station (hub) location is not determined, the hub hub and other rail way at the same time optimization problem, this problem is more common in urban rail and bus connection hub;

Comprehensive hub location: that is, the above two types of site selection of the comprehensive situation, in a variety of modes of transport convergence of the hub is more common.

\section{SUMMARY}

The optimization of railway station spacing is mainly concerned with the total travel time of passengers, but the cost of the station and the operation cost of the line and station are also important factors. Domestic research on the distance between stations is less, it is generally believed that the urban area is about $1 \mathrm{Km}$, mainly according to the importance of Urban Road intersection, traffic distribution points and the concentration of the population to set the site. In this paper, [6] is used to minimize the total travel time of the passengers on the line, and the optimal distance between buses is studied under the assumption that the distribution of passenger flow is equal; The [7][8] of passengers with average travel length for the given conditions, the average travel time of the passengers as the optimizing goal, establishes a simplified optimization method from the optimal track line station, but did not discuss details from improving the overall travel efficiency, speed and attract traffic etc..

\section{REFERENCE}

[1] Ye Xiafei, Gu Baonan, city rail transit planning and design [M] Beijing: Chinese Railway Press, 1999.101-109

[2] Shi Zhongheng, design and construction of underground railway [M], Beijing: China Railway Press, 1999.91-92

[3] Liu Huimin, the construction and algorithm of attraction area model for rail transit station [J], Journal of Changsha Jiaotong University, 2002.9:482-485 Liu Weihua, Liu Huimin,

[4] study on the attraction region of the loop of the track traffic circle [J], Journal of Changsha Railway Institute, 2002.9 Vol.20

[5] Wang Shusheng, study on the theory and method of passenger flow forecast for urban rail transit [D]. Master Thesis of Southeast University, 2004-4

[6] Zheng Zuwu et al. Modern urban traffic [M]. Beijing: China Communications Press, 1998

[7] Transportation and Traffic Engineering Handbook[Z], ITE, 2nd Edition, 1992

[8] Göran Tegnér,Personal Automated Transportat ion:Status and Potential of Personal Rapid Transit[J], Ridership Analysis. January 2003. 